\title{
Alzheimer disease biomarkers may aid in the prognosis of MCI cases initially reverted to normal
}

Lisa Vermunt, MD, Alegría J.L. van Paasen, BSc, Charlotte E. Teunissen, PhD, Philip Scheltens, MD, PhD, Pieter Jelle Visser, MD, PhD, and Betty M. Tijms, PhD, for the Alzheimer's Disease Neuroimaging Initiative Neurology ${ }^{\circledR}$ 2019;92:e2699-e2705. doi:10.1212/WNL.0000000000007609

\section{Abstract}

\section{Objective}

To identify potential predictors for outcome in individuals with mild cognitive impairment (MCI) who have reverted to normal cognition (NC).

\section{Methods}

We selected individuals with MCI, who reverted at follow-up to NC, with follow-up after reversion from Alzheimer's Disease Neuroimaging Initiative. Common clinical markers, Alzheimer disease $(\mathrm{AD})$ biomarkers, and neurodegeneration imaging markers were used to compare MCI reverters based on subsequent clinical outcome (i.e., subsequent decline or stable reversion). For independent comparison, findings of the clinical Amsterdam Dementia Cohort are presented.

\section{Results}

Seventy-seven (10\%) out of 757 individuals with MCI reverted to NC and 61 of these individuals had follow-up data available. After $3.2 \pm 2.2$ years, 16 (24\%) progressed to MCI, and 3 (5\%) to dementia. Those who declined were older and had a higher amyloid PET burden and higher CSF tau levels.

\section{Conclusion}

In $\mathrm{MCI}$ reverters, abnormal biomarkers for $\mathrm{AD}$ pathology are associated with subsequent decline. $\mathrm{AD}$ biomarkers may aid in the prognosis of reverting MCI.

\author{
Correspondence \\ Dr. Vermunt \\ I.vermunt@vumc.nl
}




\section{Glossary}

$\mathbf{A} \beta_{1-42}=\beta$-amyloid 1-42; $\mathbf{A D}=$ Alzheimer disease $\mathbf{A D C}=$ Amsterdam Dementia Cohort ADNI $=$ Alzheimer's Disease Neuroimaging Initiative; GDS = Geriatric Depression Scale; HV = hippocampal volume; $\mathbf{M C I}=$ mild cognitive impairment; $\mathbf{N C}=$ normal cognition; $\mathbf{P i B}=$ Pittsburgh compound $\mathrm{B} ; \mathbf{S U V r}=$ standard uptake value ratio; $\mathbf{t}$-tau = total tau .

Individuals with mild cognitive impairment (MCI) are at increased risk to develop dementia. ${ }^{1}$ Yet, up to $25 \%$ of individuals with $\mathrm{MCI}$ revert to normal cognition (NC). ${ }^{2,3}$ Although improved cognition seems to be a positive event, individuals reverting from MCI remain at increased risk to develop dementia compared to NC individuals. ${ }^{1,45}$ Timely identification of individuals with a higher risk will increase prognostic certainty for patients and be useful for health care planning.

In individuals with $\mathrm{NC}$ and $\mathrm{MCI}$, low memory function, abnormal biomarkers for Alzheimer disease (AD), and neurodegeneration predict dementia. ${ }^{6,7}$ While MCI reverters deviate from the common clinical trajectory, the same disease processes may be underlying. Our aim was to investigate whether MCI reverters who subsequently showed clinical decline have more abnormal $\mathrm{AD}$ markers than $\mathrm{MCI}$ reverters who remain stable.

\section{Methods}

\section{Participants}

Data analyzed were obtained from the Alzheimer's Disease Neuroimaging Initiative (ADNI) database (adni.loni.usc.edu, downloaded on August 9, 2017). From the individuals with at least 2 years clinical follow-up, we selected all individuals with prevalent and incident $\mathrm{MCI}$ reverting to $\mathrm{NC}$ with additional follow-up after reversion. ${ }^{8}$ The ADNI was launched in 2003 as a public-private partnership, led by Principal Investigator Michael W. Weiner, MD. The goal of ADNI has been to test whether serial MRI, PET, other biological markers, and clinical and neuropsychological assessment can measure progression to $\mathrm{MCI}$ and early $\mathrm{AD}$. Next to the primary analyses in ADNI, we selected from the Amsterdam Dementia Cohort (ADC) all MCI reverters with follow-up after reversion. Similar clinical and biomarker assessments are presented for this small, independent clinical sample for illustration purposes only (for cohort and biomarker methods ${ }^{9}$ ).

\section{Standard protocol approvals, registrations, and participant consents}

All protocols were approved by an ethical review board and participants signed informed consent.

\section{Clinical markers and APOE}

All individuals had baseline data on age, sex, and education. APOE genotype was dichotomized into $\varepsilon 4$ carriers and noncarriers. Overall cognitive status was assessed by the MiniMental State Examination, memory by the Rey Auditory Verbal Learning Test immediate (0-75) and delayed total recall (0-15), executive function by the Trial-Making Test $\mathrm{A}$ and $\mathrm{B}$ (seconds), and depressive symptoms by the Geriatric Depression Scale (GDS) (0-15). Subthreshold depression was classified as GDS $>4{ }^{10}$

\section{Biomarkers of $A D$ and neurodegeneration}

We studied CSF $\beta$-amyloid 1-42 (A $\left.\beta_{1-42}\right)$ and total tau ( $\mathrm{t}$-tau) (Luminex in $\mathrm{ADNI}^{11}$; Innotest in $\mathrm{ADC}^{12}$ ) and amyloid PET (florbetapir and Pittsburgh compound $\mathrm{B}[\mathrm{PiB}]$ ) as markers for $\mathrm{AD}$ pathology. $\mathrm{PiB}$ scans were harmonized to florbetapir by new value $=\mathrm{PiB}$ standard uptake value ratio $(\mathrm{SUVr}){ }^{*} 0.67$ $+0.15 .^{13}$ For imaging markers of neurodegeneration, we studied FDG-PET, hippocampal volume (HV; UCSF in Freesurfer v4.4/v5.1), normalized to total intracranial volume, and white matter hyperintensity volume. ${ }^{14}$ Cut points for abnormality for dichotomized analysis in ADNI were as follows: CSF $A \beta_{1-42}<192 \mathrm{pg} / \mathrm{mL}$, CSF t-tau $>93 \mathrm{pg} / \mathrm{mL}$, amyloid PET SUVr > 1.10, FDG-PET SUVr METAROI < 1.21 , and raw $\mathrm{HV}<6,732 \mathrm{~mm}^{3}$ (see references 11, 12, 15, and 16 for procedures and processing). Data collected within 1 year before or after MCI diagnosis were included.

\section{Statistical analysis}

MCI reverters with NC at last follow-up and MCI reverters with subsequent decline were compared on clinical and biomarkers using $\chi^{2}$, Wilcoxon, and $t$ tests when appropriate. We report results unadjusted and adjusted for age, sex, education, and $A P O E \& 4$ genotype with univariate linear regression models, and scaling of continuous outcomes, to facilitate comparability of effects.

\section{Data-sharing statement}

Data used for this study are available from the corresponding author, upon reasonable request.

\section{Results}

In ADNI, 757 individuals with prevalent or incident $\mathrm{MCI}$ had been followed for at least 2 years (figure 1). Of these, 77 $(10 \%)$ reverted to NC, and 61 (79\%) had additional follow-up available. After $3.2 \pm 2.2$ years (mean \pm SD), 16 (24\%) had converted to $\mathrm{MCI}$, and 3 (5\%) to dementia. One individual was excluded, due to missing data.

MCI reverters who showed subsequent clinical decline were on average 5 years older than reverters remaining NC, and had, adjusted for age, sex, education, and APOE, higher and more often abnormal $\mathrm{AD}$ biomarkers (amyloid PET and CSF t-tau), less impaired memory, and higher GDS scores 

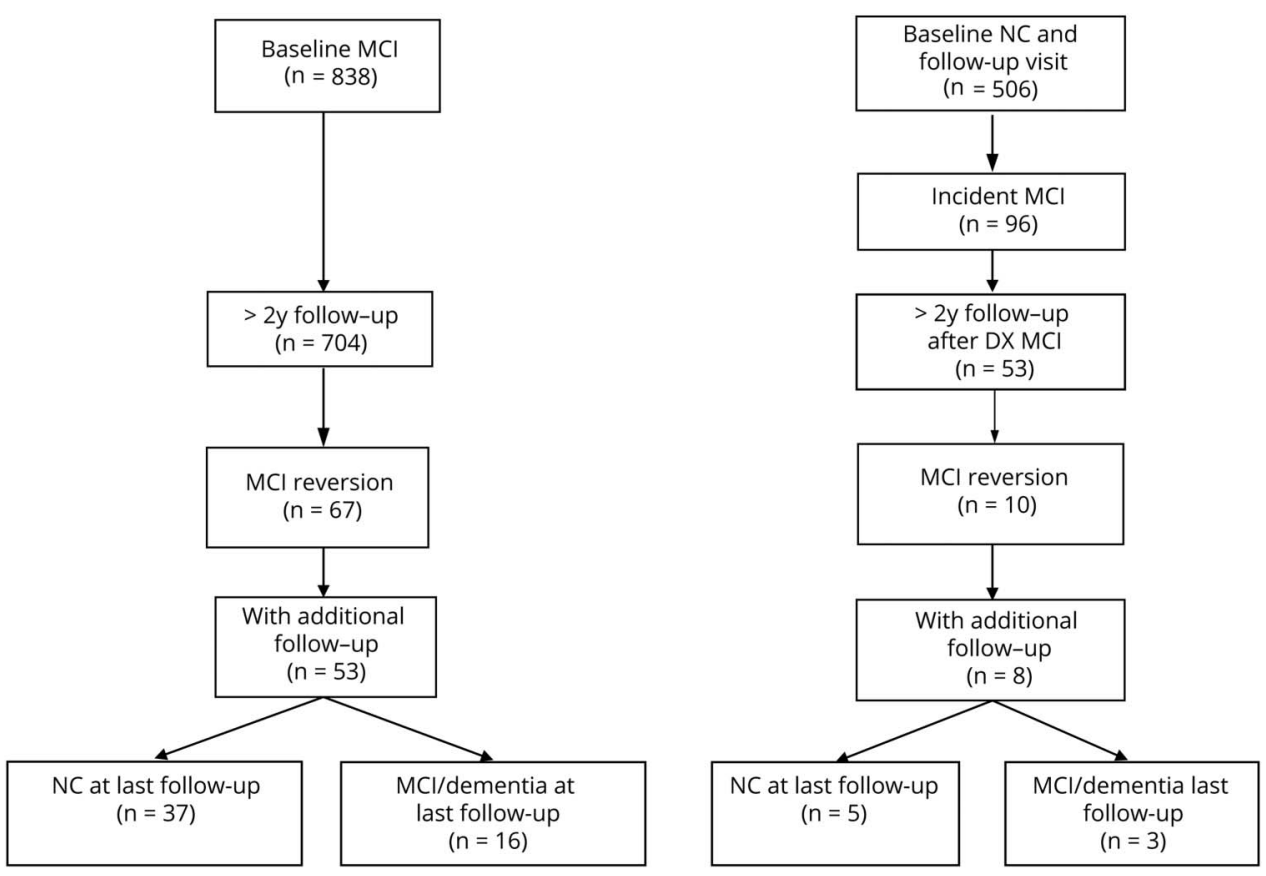

$\mathrm{DX}=$ diagnosis; $\mathrm{FU}=$ follow-up visit; $\mathrm{MCl}=$ mild cognitive impairment; $\mathrm{NC}=$ cognitively normal.

(table and figure 2). Follow-up after reversion seemed slightly shorter for stable MCI reverters $(p=0.11)$. Repeating analyses including this covariate did not essentially change the results (table e-1, doi.org/10.5061/dryad. 04n8502).

Post hoc analyses further showed that biomarkers of MCI reverters were on average more similar to NC than nonreverting MCI, except for amyloid, which was more often abnormal in MCI reverters than in NC (table e-2, doi.org/10. 5061/dryad.04n8502). Still, MCI reverters showed higher clinical progression rates (110/1,000 person-years) compared to baseline NC (52/1,000 person-years, hazard ratio [95\% confidence interval] 2.3 [1.4-4.0], $p=0.002$ ) (table e-3 and figure e-1, doi.org/10.5061/dryad.04n8502). The biomarker associations with progression were similar for $\mathrm{NC}$ and $\mathrm{MCI}$ reverters, whereas associations with progression and cognitive test scores were less consistent (table e- 4 and figure e-2, doi. org/10.5061/dryad.04n8502).

\section{Outcome of $\mathrm{MCI}$ reverters in clinical ADC cohort}

In the ADC, of 735 patients with $\mathrm{MCI}$ and a follow-up visit, 75 (10\%) reverted to NC. Twenty-six (35\%) patients had $1.6 \pm$ 0.8 years (mean \pm SD) follow-up available after reversion, after which 24 (92\%) remained NC and 2 (8\%) had dementia. Small group size precluded formal statistical testing. The 2 decliners had abnormal CSF $A \beta_{1-42}$ and t-tau (table). The majority of individuals remaining NC had normal CSF A $\beta_{1-42}$ $(80 \%)$ and t-tau (85\%). Thirty-two percent of the stable reverters showed baseline subthreshold depression.

\section{Discussion}

Age and $\mathrm{AD}$ biomarkers are associated with decline in patients with MCI who initially reverted to normal cognition. MCI reverters showed higher clinical progression rates than NC individuals, which is in line with previous reports. ${ }^{1,4} \mathrm{MCI}$ reverters with subsequent decline had an increased amyloid PET burden and CSF tau compared to reverters remaining normal. Between amyloid markers, amyloid PET showed a significant association with the subsequent decline group in MCI reverters, while this association was significant for CSF $A \beta_{1-42}$ in NC. Although previous research suggests that CSF amyloid becomes abnormal before PET, ${ }^{17,18}$ the findings are in line with other reports that this may not apply to all individuals, ${ }^{19,20}$ which contributes to the notion that CSF $A \beta_{1-42}$ and amyloid PET may represent different $A D$-related processes.

An outstanding question is why individuals with underlying $\mathrm{AD}$ temporarily improved. Our results suggest that at baseline, MCI reverters were more similar to NC than nonreverting MCI. Furthermore, biomarker values associated with subsequent decline were similar for reverting MCI and NC, while cognitive measures were less consistent. Possibly, reverters with decline received an MCI diagnosis very early in their clinical disease course, as their biomarker profiles were like the nonreverting MCI. A modest improvement, for example, due to learning effects, resolving of (subthreshold) depressive symptoms, or measurement error, may have contributed to reclassification as normal. Here we observed that when $\mathrm{AD}$ is present, such improvement is often not lasting. 
Table Mild cognitive impairment (MCI) reverters with follow-up of Alzheimer's Disease Neuroimaging Initiative (ADNI) and Amsterdam Dementia Cohort (ADC)

\begin{tabular}{|c|c|c|c|c|c|c|}
\hline & \multicolumn{4}{|c|}{ ADNI MCI reverters } & \multicolumn{2}{|c|}{$\mathrm{ADC} \mathrm{MCl}$ reverters } \\
\hline & $\begin{array}{l}\text { Persistent } \\
\text { normal } \\
\text { cognition } \\
(n=42)\end{array}$ & $\begin{array}{l}\text { Decline to } \mathrm{MCl} \\
\text { or dementia } \\
(\mathrm{n}=19)\end{array}$ & $\begin{array}{l}p \text { Value ADNI } \\
\text { group } \\
\text { comparison }\end{array}$ & $\begin{array}{l}p \text { Value adjusted for } \\
\text { age, sex, education, } \\
\text { APOE \&4 }\end{array}$ & $\begin{array}{l}\text { Persistent } \\
\text { normal } \\
\text { cognition } \\
(n=24)\end{array}$ & $\begin{array}{l}\text { Decline to } \mathrm{MCl} \\
\text { or dementia } \\
(\mathrm{n}=2)\end{array}$ \\
\hline \multicolumn{7}{|l|}{ Baseline characteristics } \\
\hline Age, y & $69(8)$ & $74(8)$ & $0.016^{\mathrm{a}}$ & NA & $65(7)$ & $71(7)$ \\
\hline Female, \% & 50 & 26 & 0.146 & NA & 29 & 100 \\
\hline $\begin{array}{l}\text { Education, ADNI, y; ADC, } \\
\text { Verhage scale }\end{array}$ & $17.2(2.6)$ & $16.3(2.0)$ & $0.095^{b}$ & NA & $5(1.4)$ & $5(1.4)$ \\
\hline APOE $\varepsilon 4$ carrier, $\%$ & 38 & 32 & 0.839 & NA & 46 & 50 \\
\hline \multicolumn{7}{|l|}{ Follow-up } \\
\hline $\begin{array}{l}\text { Total follow-up, y, median } \\
\text { (IQR) }\end{array}$ & $4(2.3)$ & $5(2.5)$ & 0.109 & NA & $3.0(1.8)$ & $5.3(1.6)$ \\
\hline $\begin{array}{l}\text { Time to reversion, } y, \\
\text { median (IQR) }\end{array}$ & $1(1.8)$ & $2(2)$ & 0.462 & NA & $1.3(1.0)$ & $1.8(0.7)$ \\
\hline $\begin{array}{l}\text { Follow-up after reversion, } y \text {, } \\
\text { median (IQR) }\end{array}$ & $2(1.8)$ & $3(2)$ & 0.265 & NA & $1.4(0.9)$ & $3.6(1.0)$ \\
\hline $\begin{array}{l}\text { Time to progression after } \\
\text { reversion, } y \text {, median (IQR) }\end{array}$ & NA & $1(1)$ & NA & NA & NA & $1(0)$ \\
\hline $\mathrm{N}$ with $>1$ reversion & 4 & 2 & $>0.99$ & NA & 2 & 1 \\
\hline \multicolumn{7}{|l|}{ Clinical } \\
\hline MMSE & $28.7(1.4)$ & $28.3(1.8)$ & 0.573 & 0.904 & $27.5(1.6)$ & 29 \\
\hline $\begin{array}{l}\text { RAVLT immediate total } \\
\text { recall }\end{array}$ & $43(11)$ & $47(12)$ & 0.262 & $0.002^{\mathrm{a}}$ & $36(10)$ & 19 \\
\hline RAVLT delayed total recall & $6.6(4.2)$ & $8.3(4.6)$ & 0.185 & $0.002^{\mathrm{a}}$ & $5.6(1.6)$ & 3 \\
\hline Trail-Making Test A & $31(10)$ & $34(11)$ & 0.496 & 0.700 & $38(11)$ & $44(1)$ \\
\hline Trail-Making Test B & $72(24)$ & $80(31)$ & 0.362 & 0.973 & $90(36)$ & $94(30)$ \\
\hline GDS & $1.1(1)$ & $1.6(2)$ & 0.138 & $0.018^{a}$ & $3.7(3)$ & $3.5(2)$ \\
\hline GDS > $4, n(\%)$ & $2(5)$ & $1(5)$ & $>0.99$ & 0.508 & $7(32)$ & $1(50)$ \\
\hline \multicolumn{7}{|l|}{ AD biomarkers } \\
\hline Amyloid PET, SUVr & $1.08(0.15)$ & $1.21(0.21)$ & $0.026^{a}$ & $0.016^{a}$ & - & - \\
\hline $\begin{array}{l}\text { Amyloid PET, n SUVr > } \\
1.10(\%)\end{array}$ & $10(30)$ & $9(64)$ & $0.065^{\mathrm{b}}$ & $0.018^{\mathrm{a}}$ & - & - \\
\hline Luminex $\operatorname{CSF} A \beta_{1-42}, \mathrm{pg} / \mathrm{mL}^{\mathrm{c}}$ & $218(45)^{\mathrm{b}}$ & $190(65)^{b}$ & 0.214 & 0.213 & - & - \\
\hline Innotest CSF $A \beta_{1-42}, \mathrm{pg} / \mathrm{mL}^{\mathrm{c}}$ & - & - & & & $1,047(243)^{c}$ & $780(5)^{c}$ \\
\hline Abnormal CSF $A \beta_{1-42}, n(\%)^{c}$ & $9(31)$ & $5(45)$ & 0.629 & 0.455 & $4(20)$ & $2(100)$ \\
\hline $\begin{array}{l}\text { Luminex CSF t-tau, } \\
\mathrm{pg} / \mathrm{mL}^{\mathrm{c}}\end{array}$ & $53(17)^{b}$ & $84(42)^{b}$ & $0.042^{\mathrm{a}}$ & $0.020^{\mathrm{a}}$ & - & - \\
\hline $\begin{array}{l}\text { Innotest CSF t-tau, } \\
\mathrm{pg} / \mathrm{mL}^{\mathrm{c}}\end{array}$ & - & - & & & $284(140)^{c}$ & $955(24)$ \\
\hline $\begin{array}{l}\text { Abnormal CSF t-tau, } \\
\mathrm{n}(\%)^{\mathrm{c}}\end{array}$ & $0(0)$ & $3(27)$ & $0.024^{a}$ & $0.009^{a}$ & $3(15)$ & $2(100)$ \\
\hline
\end{tabular}


Table Mild cognitive impairment (MCI) reverters with follow-up of Alzheimer's Disease Neuroimaging Initiative (ADNI) and Amsterdam Dementia Cohort (ADC) (continued)

\begin{tabular}{|c|c|c|c|c|c|c|}
\hline & \multicolumn{4}{|c|}{ ADNI MCI reverters } & \multicolumn{2}{|c|}{$\mathrm{ADC} \mathrm{MCl}$ reverters } \\
\hline & $\begin{array}{l}\text { Persistent } \\
\text { normal } \\
\text { cognition } \\
(n=42)\end{array}$ & $\begin{array}{l}\text { Decline to } \mathrm{MCl} \\
\text { or dementia } \\
(\mathrm{n}=19)\end{array}$ & $\begin{array}{l}p \text { Value ADNI } \\
\text { group } \\
\text { comparison }\end{array}$ & $\begin{array}{l}p \text { Value adjusted for } \\
\text { age, sex, education, } \\
\text { APOE \&4 }\end{array}$ & $\begin{array}{l}\text { Persistent } \\
\text { normal } \\
\text { cognition } \\
(n=24)\end{array}$ & $\begin{array}{l}\text { Decline to MC } \\
\text { or dementia } \\
(n=2)\end{array}$ \\
\hline \multicolumn{7}{|l|}{$\begin{array}{l}\text { Imaging markers of } \\
\text { neurodegeneration }\end{array}$} \\
\hline FDG-PET METAROI, SUVr & $1.34(0.11)$ & $1.27(0.14)$ & $0.051^{\mathrm{b}}$ & 0.458 & - & - \\
\hline $\begin{array}{l}\text { FDG-PET METAROI, SUVr }< \\
1.21, \mathrm{n}(\%)\end{array}$ & $5(13)$ & $6(35)$ & 0.126 & 0.627 & - & - \\
\hline $\begin{array}{l}\text { Hippocampus/intracranial } \\
\text { volume, } \mathrm{cm}^{3}\end{array}$ & $0.48(0.07)$ & $0.42(0.09)$ & 0.092 & 0.591 & - & - \\
\hline $\begin{array}{l}\text { Hippocampus volume }< \\
6,673 \mathrm{~mm}^{3}, \mathrm{n}(\%)\end{array}$ & $6(27)$ & $5(56)$ & 0.280 & 0.731 & - & - \\
\hline $\begin{array}{l}\text { White matter } \\
\text { hyperintensities volume, } \\
\mathrm{cm}^{3}\end{array}$ & $1.80(2.69)$ & $4.29(6.24)$ & 0.263 & $0.054^{\mathrm{b}}$ & - & - \\
\hline
\end{tabular}

Abbreviations: $A \beta_{1-42}=\beta$-amyloid 1-42; GDS = Geriatric Depression Scale; IQR = interquartile range; MMSE = Mini-Mental State Examination; RAVLT = Rey Auditory Verbal Learning Test; SUVr = standard uptake value ratio.

Sample sizes in ADNI: amyloid PET: $n=47 ;$ FDG-PET: $n=55$; MRI hippocampal volume: $n=31 ;$ white matter hyperintensities: $n=58$; CSF: $n=40$. Sample sizes in ADC: RAVLT: $n=24 ;$ GDS: $n=24 ;$ CSF: $n=22$. Data are mean (SD) unless otherwise specified.

${ }^{a} p<0.05$.

${ }^{\mathrm{b}} p<0.10$.

'For ADNI: Luminex assay abnormality threshold: CSF $A \beta_{1-42}<192 \mathrm{pg} / \mathrm{mL}$, total tau $>93 \mathrm{pg} / \mathrm{mL}$; in $A D C$ Innotest values corrected for upwards drift with abnormality thresholds CSF $A \beta_{1-42}<813 \mathrm{pg} / \mathrm{mL}$; total tau $>375 \mathrm{pg} / \mathrm{mL}$.

Verhage scale ranges from 1 to 7.

Furthermore, it remains unclear as to why individuals who reverted and remained $\mathrm{NC}$ over time were initially diagnosed with MCI. Aside neurodegenerative diseases, depressive symptoms are a common cause of MCI. Low depressive symptoms scores in ADNI reflect inclusion criteria. In the ADC, subthreshold depression was more common. Another possibility is that distress or insecurity led to a suboptimal performance. The question remains how to deal with the classification of these individuals in the context of $\mathrm{AD}$ progression research, when $\mathrm{MCI}$ is often regarded as an intermediate disease stage. A practical implementation could be to classify reverting MCI with normal biomarkers as NC. Alternatively, including stability of the diagnosis in the classification has been suggested. ${ }^{4}$

A limitation of this study is the relatively short follow-up time, and so we cannot exclude the possibility that some individuals in the stable group may progress again. Compared to populationbased studies, reversion rates in both cohorts were low. ${ }^{3}$ Possibly, this reflects that clinicians will not easily reverse a known diagnosis. Reversion rates may even be lower, because we based reversion rates on individuals with $\mathrm{MCI}$ who met our inclusion criteria. Individuals with MCI excluded from these analyses as they were lost to follow-up were somewhat older and more cognitively impaired, which are characteristics that associate with decline $^{1}$ (table e-5, doi.org/10.5061/dryad.04n8502). Although further replication in large population-based studies is necessary, our results suggest that $\mathrm{AD}$ biomarkers aid in the prognosis of
MCI reverters, and could help to identify those with a good short term prognosis and those likely to decline again in the longer term.

\section{Acknowledgment}

The authors thank the participants and patients for their contributions, as well as staff involved at ADNI and the Amsterdam Dementia Cohort for data collection and data sharing.

\section{Study funding}

This work has been supported by ZonMW Memorabel grant program \#73305056 (B.M.T.) and \#733050824 (B.M.T. and P.J.V.) and the Innovative Medicines Initiative Joint Undertaking under grant agreement n115736, resources of which are composed of financial contribution from the European Union's Seventh Framework Programme (FP7/2007-2013) and EFPIA companies' in kind contribution. The Amsterdam Dementia Cohort part of the VUmc Alzheimer Center is supported by Stichting Alzheimer Nederland and Stichting VUmc fonds. The clinical database structure was developed with funding from Stichting Dioraphte. Data collection and sharing for the ADNI project was funded by ADNI (NIH grant U01 AG024904) and DOD ADNI (Department of Defense award number W81XWH-12-2-0012). ADNI is funded by the National Institute on Aging, the National Institute of Biomedical Imaging and Bioengineering, and through contributions from the following: AbbVie; Alzheimer's Association; Alzheimer's Drug 
Figure 2 Standardized $\beta$ s: Alzheimer disease (AD) clinical markers and biomarkers for decliner group
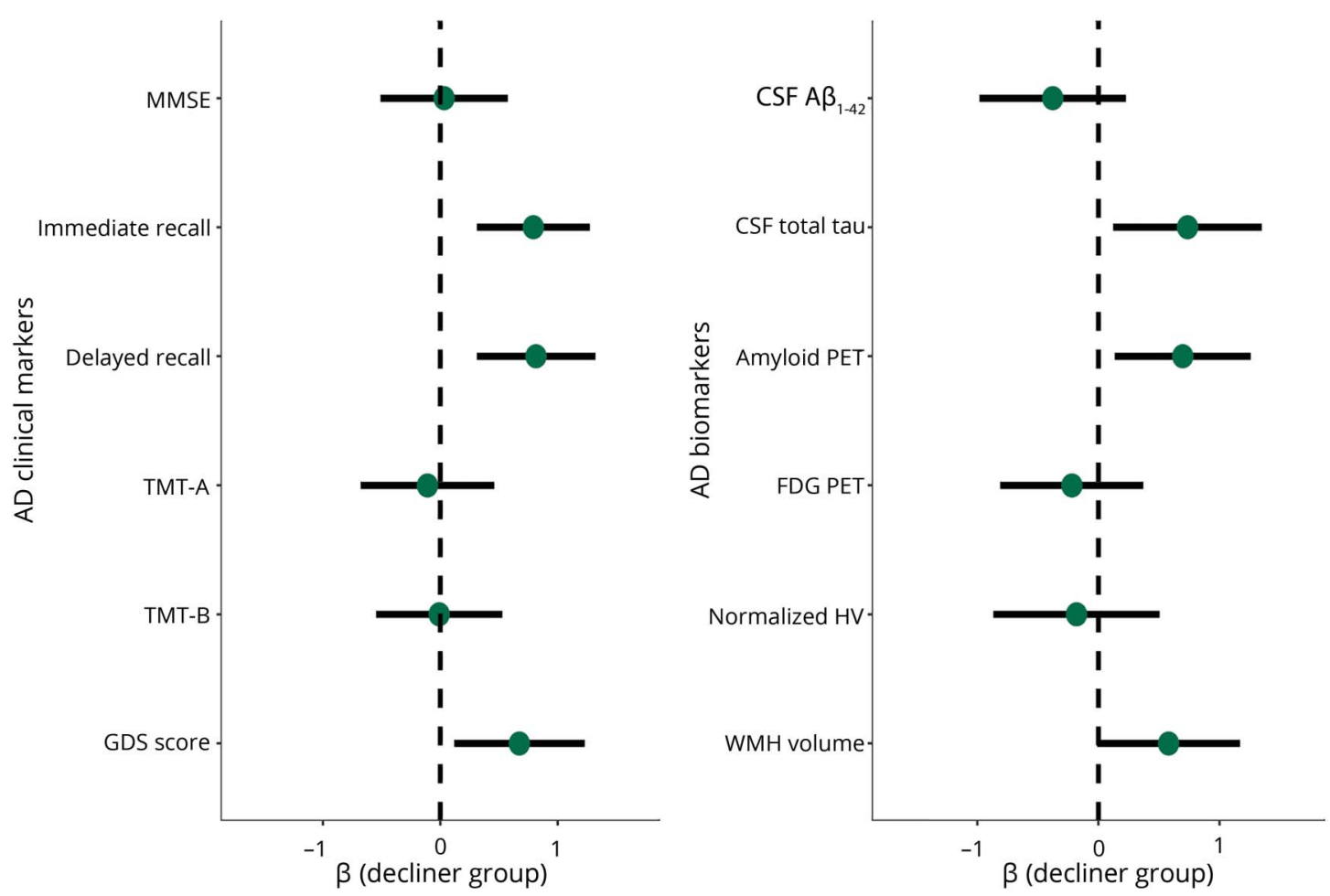

Immediate and delayed recall of the Rey Auditory Verbal Learning Test, Trail-Making Test (TMT), Geriatric Depression Scale (GDS), white matter hyperintensities (WMH), and hippocampal volume (HV). Models were adjusted for age, sex, education, and APOE $\varepsilon 4$.

Discovery Foundation; Araclon Biotech; BioClinica, Inc.; Biogen; Bristol-Myers Squibb Company; CereSpir, Inc.; Cogstate; Eisai Inc.; Elan Pharmaceuticals, Inc.; Eli Lilly and Company; EuroImmun; F. Hoffmann-La Roche Ltd. and its affiliated company Genentech, Inc.; Fujirebio; GE Healthcare; IXICO Ltd.; Janssen Alzheimer Immunotherapy Research \& Development, LLC; Johnson \& Johnson Pharmaceutical Research \& Development LLC; Lumosity; Lundbeck; Merck \& Co., Inc.; Meso Scale Diagnostics, LLC; NeuroRx Research; Neurotrack Technologies; Novartis Pharmaceuticals Corporation; Pfizer Inc.; Piramal Imaging; Servier; Takeda Pharmaceutical Company; and Transition Therapeutics. The Canadian Institutes of Health Research is providing funds to support ADNI clinical sites in Canada. Private sector contributions are facilitated by the Foundation for the NIH (fnih.org). The grantee organization is the Northern California Institute for Research and Education, and the study is coordinated by the Alzheimer's Therapeutic Research Institute at the University of Southern California. ADNI data are disseminated by the Laboratory for Neuro Imaging at the University of Southern California.

\section{Disclosure}

L. Vermunt and A. van Paassen report no disclosures relevant to the manuscript. C. Teunissen reports being a member of the international advisory board at Innogenetics and Roche and having research contracts at Probiodrug, Boehringer, Roche, EIP Pharma, and IBL. P. Scheltens has acquired grant support (for the institution) from GE Healthcare, Nutricia Research, Piramal, and MERCK. In the last 2 years, he has received consultancy/speaker fees (paid to the institution) from Lilly, Biogen, Novartis, Probiodrug, Roche, and EIP Pharma. P. Visser reports receiving research support from Biogen, grants from the European Federation of Pharmaceutical Industries and Associations (EFPIA) Innovative Medicines Initiative Joint Undertaking, EU Joint Programme-Neurodegenerative Disease Research, ZonMw, and Bristol-Myers Squibb; having served as member of the advisory board of Roche Diagnostics; and having received nonfinancial support from GE Healthcare. B. Tijms reports no disclosures relevant to the manuscript. Go to Neurology.org/N for full disclosures.

\section{Publication history}

Received by Neurology October 9, 2018. Accepted in final form February $1,2019$.

\section{Appendix Authors}

\begin{tabular}{|c|c|c|c|}
\hline Name & Location & Role & Contribution \\
\hline $\begin{array}{l}\text { L. } \\
\text { Vermunt, } \\
\text { MD }\end{array}$ & $\begin{array}{l}\text { Amsterdam } \\
\text { UMC, the } \\
\text { Netherlands }\end{array}$ & Author & $\begin{array}{l}\text { Designed and } \\
\text { conceptualized study, } \\
\text { analyzed the data, drafted } \\
\text { and revised the manuscript } \\
\text { for intellectual content }\end{array}$ \\
\hline
\end{tabular}




\section{Appendix (continued)}

\begin{tabular}{|c|c|c|c|}
\hline Name & Location & Role & Contribution \\
\hline $\begin{array}{l}\text { A.J.L. van } \\
\text { Paasen, } \\
\text { BSc }\end{array}$ & $\begin{array}{l}\text { Amsterdam } \\
\text { UMC, the } \\
\text { Netherlands }\end{array}$ & Coauthor & $\begin{array}{l}\text { Interpreted the data, revised } \\
\text { the manuscript for } \\
\text { intellectual content }\end{array}$ \\
\hline $\begin{array}{l}\text { C.E. } \\
\text { Teunissen, } \\
\text { PhD }\end{array}$ & $\begin{array}{l}\text { Amsterdam } \\
\text { UMC, the } \\
\text { Netherlands }\end{array}$ & Coauthor & $\begin{array}{l}\text { Interpreted the data, } \\
\text { analyzed the data, revised } \\
\text { the manuscript for } \\
\text { intellectual content }\end{array}$ \\
\hline $\begin{array}{l}\text { P. } \\
\text { Scheltens, } \\
\text { MD, PhD }\end{array}$ & $\begin{array}{l}\text { Amsterdam } \\
\text { UMC, the } \\
\text { Netherlands }\end{array}$ & Coauthor & $\begin{array}{l}\text { Interpreted the data, revised } \\
\text { the manuscript for } \\
\text { intellectual content }\end{array}$ \\
\hline $\begin{array}{l}\text { P.J. Visser, } \\
\text { MD, PhD }\end{array}$ & $\begin{array}{l}\text { Amsterdam } \\
\text { UMC, the } \\
\text { Netherlands }\end{array}$ & Coauthor & $\begin{array}{l}\text { Interpreted the data, revised } \\
\text { the manuscript for } \\
\text { intellectual content }\end{array}$ \\
\hline $\begin{array}{l}\text { B.M. Tijms, } \\
\text { PhD }\end{array}$ & $\begin{array}{l}\text { Amsterdam } \\
\text { UMC, the } \\
\text { Netherlands }\end{array}$ & $\begin{array}{l}\text { Senior } \\
\text { author }\end{array}$ & $\begin{array}{l}\text { Designed and } \\
\text { conceptualized study, } \\
\text { analyzed the data, } \\
\text { interpreted the data, writing, } \\
\text { revised the manuscript for } \\
\text { intellectual content }\end{array}$ \\
\hline
\end{tabular}

\section{References}

1. Roberts RO, Knopman DS, Mielke MM, et al. Higher risk of progression to dementia in mild cognitive impairment cases who revert to normal. Neurology 2014;82: 317-325.

2. Malek-Ahmadi M. Reversion from mild cognitive impairment to normal cognition: a meta-analysis. Alzheimer Dis Assoc Disord 2016;30:324-330.

3. Canevelli M, Grande G, Lacorte E, et al. Spontaneous reversion of mild cognitive impairment to normal cognition: a systematic review of literature and meta-analysis. J Am Med Dir Assoc 2016;17:943-948.

4. Aerts L, Heffernan M, Kochan NA, et al. Effects of MCI subtype and reversion on progression to dementia in a community sample. Neurology 2017;88:2225-2232.
5. Koepsell TD, Monsell SE. Reversion from mild cognitive impairment to normal or near-normal cognition: risk factors and prognosis. Neurology 2012;79:1591-1598.

6. Jack CR Jr, Bennett DA, Blennow K, et al. NIA-AA Research Framework: toward a biological definition of Alzheimer's disease. Alzheimers Dement 2018;14: 535-562.

7. Visser PJ, Verhey F, Knol DL, et al. Prevalence and prognostic value of CSF markers of Alzheimer's disease pathology in patients with subjective cognitive impairment or mild cognitive impairment in the DESCRIPA study: a prospective cohort study. Lancet Neurol 2009;8:619-627.

8. Petersen RC, Aisen PS, Beckett LA, et al. Alzheimer's Disease Neuroimaging Initiative (ADNI): clinical characterization. Neurology 2010;74:201-209.

9. van der Flier WM, Pijnenburg YA, Prins N, et al. Optimizing patient care and research: the Amsterdam Dementia Cohort. J Alzheimers Dis 2014;41:313-327.

10. Pocklington C, Gilbody S, Manea L, McMillan D. The diagnostic accuracy of brief versions of the Geriatric Depression Scale: a systematic review and meta-analysis. Int J Geriatr Psychiatry 2016;31:837-857.

11. Shaw LM, Vanderstichele H, Knapik-Czajka M, et al. Cerebrospinal fluid biomarker signature in Alzheimer's disease neuroimaging initiative subjects. Ann Neurol 2009; 65:403-413.

12. Tijms BM, Willemse EAJ, Zwan MD, et al. Unbiased approach to counteract upward drift in cerebrospinal fluid amyloid-beta 1-42 analysis results. Clin Chem 2018;64: 576-585.

13. Landau SM, Breault C, Joshi AD, et al. Amyloid-beta imaging with Pittsburgh compound B and florbetapir: comparing radiotracers and quantification methods. J Nucl Med 2013;54:70-77.

14. Decarli CMP, Fletcher E. Four tissue segmentation in ADNI II; 2013. Available at: alz. washington.edu/WEB/adni proto.pdf. Accessed August 16, 2018.

15. Jack CR Jr, Bernstein MA, Fox NC, et al. The Alzheimer's Disease Neuroimaging Initiative (ADNI): MRI methods. J Magn Reson Imaging 2008;27:685-691.

16. Landau SM, Harvey D, Madison CM, et al. Associations between cognitive, functional, and FDG-PET measures of decline in AD and MCI. Neurobiol Aging 2011;32: 1207-1218.

17. Tijms BM, Vermunt L, Zwan MD, et al. Pre-amyloid stage of Alzheimer's disease in cognitively normal individuals. Ann Clin Transl Neurol 2018;5:1037-1047.

18. Palmqvist S, Mattsson N, Hansson O; Alzheimer's Disease Neuroimaging Initiative. Cerebrospinal fluid analysis detects cerebral amyloid-beta accumulation earlier than positron emission tomography. Brain 2016;139:1226-1236.

19. Zwan M, van Harten A, Ossenkoppele R, et al. Concordance between cerebrospinal fluid biomarkers and [11C]PIB PET in a memory clinic cohort. J Alzheimers Dis 2014;41:801-807.

20. Landau $\mathrm{SM}, \mathrm{Lu} \mathrm{M}$, Joshi $\mathrm{AD}$, et al. Comparing positron emission tomography imaging and cerebrospinal fluid measurements of beta-amyloid. Ann Neurol 2013;74: $826-836$ 


\section{Neurology}

\section{Alzheimer disease biomarkers may aid in the prognosis of MCI cases initially reverted to normal}

Lisa Vermunt, Alegría J.L. van Paasen, Charlotte E. Teunissen, et al.

Neurology 2019;92;e2699-e2705 Published Online before print May 8, 2019

DOI 10.1212/WNL.0000000000007609

\section{This information is current as of May 8, 2019}

\section{Updated Information \&} Services

References

Subspecialty Collections

Permissions \& Licensing

Reprints including high resolution figures, can be found at: http://n.neurology.org/content/92/23/e2699.full

This article cites 19 articles, 6 of which you can access for free at: http://n.neurology.org/content/92/23/e2699.full\#ref-list-1

This article, along with others on similar topics, appears in the following collection(s):

Alzheimer's disease

http://n.neurology.org/cgi/collection/alzheimers_disease

Cerebrospinal Fluid

http://n.neurology.org/cgi/collection/cerebrospinal_fluid

MCI (mild cognitive impairment)

http://n.neurology.org/cgi/collection/mci_mild_cognitive_impairment

Natural history studies (prognosis)

http://n.neurology.org/cgi/collection/natural_history_studies_prognosis

\section{PET}

http://n.neurology.org/cgi/collection/pet

Information about reproducing this article in parts (figures,tables) or in its entirety can be found online at:

http://www.neurology.org/about/about_the_journal\#permissions

Information about ordering reprints can be found online:

http://n.neurology.org/subscribers/advertise

Neurology ${ }^{\circledR}$ is the official journal of the American Academy of Neurology. Published continuously since 1951, it is now a weekly with 48 issues per year. Copyright Copyright (C) 2019 The Author(s). Published by Wolters Kluwer Health, Inc. on behalf of the American Academy of Neurology.. All rights reserved. Print ISSN: 0028-3878. Online ISSN: 1526-632X.

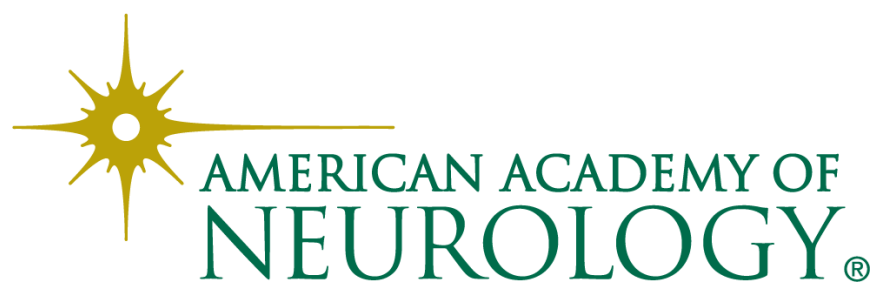

